\title{
EXPERIMENTAL RESEARCH ON THE BEHAVIOUR OF EH 36 NAVAL STEEL AT THE MAG-M MECHANIZED BUTT WELDING
}

\author{
Stefan Nabi FLORESCU \\ National Research Institute of Marine Geology \\ and Geoecology, 23-25 Dimitrie Onciul St., \\ 024053, Bucharest, Romania \\ E-mail:stefan.florescu@geoecomar.ro
}

\author{
Danut MIHAILESCU \\ "Dunarea de Jos" University of Galati, \\ Faculty of Engineering, Galati, Domneasca \\ Street, No. 47, 800008, Romania, \\ E-mail:danut.mihailescu@ugal.ro
}

\author{
Marius Corneliu GHEONEA \\ "Dunarea de Jos" University of Galati, \\ Faculty of Engineering, Galati, Domneasca \\ Street, No. 47, 800008, Romania, \\ E-mail:marius.gheonea@ugal.ro
}

\begin{abstract}
The paper presents the experimental research on the behaviour of EH 36 naval steel at the MAG-M mechanized butt welding in the naval field. Butt welded joint was performed in the four welding positions $(P A / 1 G, P C / 2 G, P F / 3 G$ and $P E / 4 G)$. In the welding process, two types of tubular wires and a mixture of active protective gases were used. The first part of the paper presents the effective welding of the four samples. The results of the nondestructive and destructive controls of the welded samples are presented below. The work is completed with the conclusions drawn from the experimental program. The good results thus obtained make it possible to apply the welding technologies of the EH 36 naval steel in the four analyzed positions.
\end{abstract}

Keywords: MAG-M mechanized butt welding, metal-cored wire, flux-cored wire

\section{INTRODUCTION}

Steels for shipbuilding are steels made with strict observance of the requirements of the classification companies (ABS, LR, BV, GL, DNV). For the construction of the body structures of maritime and river vessels, hotrolled steel sheets are used [5,7,8,9]:

- with normal resistance $\left(\mathrm{R}_{\mathrm{p} 0.2}>265\right.$ $\mathrm{MPa})$ : $\mathrm{AH} 27 \mathrm{~S}, \mathrm{DH} 27 \mathrm{~S}, \mathrm{EH} 27 \mathrm{~S}$ and $\mathrm{PH}$ $27 \mathrm{~S}$;

- with high resistance $\left(\mathrm{R}_{\mathrm{p} 0.2}>315 \mathrm{MPa}\right)$ :

- AH 32, DH 32, EH 32 and PH 32 (Rp0.2 > $315 \mathrm{MPa})$;

- AH 36, DH 36, EH 36 and PH $36\left(\mathrm{R}_{\mathrm{p} 0.2}\right.$ $>355 \mathrm{MPa}$ );
- AH 40, DH 40, EH 40 and PH $40\left(\mathrm{R}_{\mathrm{p} 0.2}\right.$ $>390 \mathrm{MPa})$;

- EH $47\left(\mathrm{R}_{\mathrm{p} 0.2}>460 \mathrm{MPa}\right)$.

In addition to normal steels, in the early 80s, High Strength Low-Alloy Steel (HSLA) was introduced into increasingly large-scale manufacturing. From the point of view of the chemical composition, the differences between the different types of naval steels are not significant. The superior mechanical properties of HSLA steels are the result of the succession of heat treatments that are applied during their elaboration. The superior mechanical characteristics of HSLA steels are due to a small extent to the presence of micro-alloying elements. These are intro- 
duced in the composition especially in order to control the metal phases and the structural constituents, but also to improve the weldability of the material. With the development of new materials with lower carbon content and alloying elements, the weldability of naval steels has improved and, in most cases, the need for preheating has been eliminated. In the field of steels up to $500 \mathrm{MPa}$, preheating is no longer necessary.

The main technical-economic criteria for the selection of the butt welding process by melting, in the naval field, are the following $[2,3,4,6]$ :

- to ensure quality welded joints, with a complete penetration of the root layer by welding from one side (from the outside) in difficult welding positions;

- to allow the use of welding regimes as productive as possible;

- to ensure a good quality of the welded joint executed in difficult climatic conditions from the mounting place (outdoors);

- the productivity of the welding process is as high as possible;

- the cost of the works and equipment for welding, checking and repairing should be as low as possible.

Due to the complexity of the technicaleconomic criteria imposed, only three welding processes $[2,3,4,6]$ can be available: 111Manual Metal Arc Welding (MMAW); 135Metal Active Gas Welding (MAGW) and 136- Flux-Cored Arc Welding (FCAW) or Metal-Cored Arc Welding (MCAW), respectively. The selection of MAGW, FCAW and MCAW mechanized welding procedures is the most recommended solution.

The use of ceramic backing allows obtaining welded joints with a very good penetration in manual, semi-mechanized, mechanized and robotic applications, in any position, eliminating the operations of twisting, polishing, filling at the root.

This solution is recommended both for obtaining a good root quality in terms of shape and metallographic structure, as well as for increasing productivity and simpli- fying the welding technology.

In this paper, the authors present the experimental research regarding the behaviour of EH 36 naval steel in MAG-M mechanized butt welding with flux-cored wires, on flat ceramic backing, in different welding positions in the naval field. The good results of the non-destructive and destructive controls, make it possible to apply the welding technologies of EH 36 naval steel with a thickness of $10 \mathrm{~mm}$ in the comfortable position $\mathrm{PA} / 1 \mathrm{G}$ and in the difficult positions $(\mathrm{PF} / 3 \mathrm{G}$, $\mathrm{PE} / 4 \mathrm{G}$ and $\mathrm{PC} / 2 \mathrm{G})$.

\section{EXPERIMENTAL PROGRAM}

\subsection{Welding materials and equipment} used:

In the experimental program, there were

- EH 36 naval steel plates, with dimensions 300x150x10 mm. The chemical composition and mechanical characteristics of EH 36 naval steel, according to the quality certificate, are presented in Table 1 and Table 2;

Table 1. Chemical compositions [1,2]

\begin{tabular}{|c|c|c|c|}
\hline \multirow{4}{*}{ Material } & $\mathrm{C}$ & $\mathrm{Mn}$ & $\mathrm{Si}$ \\
\cline { 2 - 4 } & $\mathrm{P}$ & $\mathrm{S}$ & $\mathrm{Al}$ \\
\cline { 2 - 4 } & $\mathrm{Cr}$ & $\mathrm{Ni}$ & $\mathrm{Mo}$ \\
\cline { 2 - 4 } & $\mathrm{V}$ & $\mathrm{Cu}$ & $\mathrm{Nb}$ \\
\hline \multirow{4}{*}{ EH 36 } & 0.178 & 1.3971 & 0.1999 \\
\cline { 2 - 4 } & 0.0138 & 0.0020 & 0.0517 \\
\cline { 2 - 4 } & 0.0261 & 0.0084 & 0.0042 \\
\cline { 2 - 4 } & 0.0306 & 0.0123 & 0.0385 \\
\hline \multirow{4}{*}{$\begin{array}{c}\text { E70C- } \\
\text { 6MH4 }\end{array}$} & 0.0742 & 1.578 & 0.3928 \\
\cline { 2 - 4 } & 0.0134 & 0.0074 & 0.0087 \\
\cline { 2 - 4 } & 0.0423 & 0.0257 & 0.0053 \\
\cline { 2 - 4 } & 0.001 & 0.1004 & 0.0009 \\
\hline \multirow{4}{*}{$\begin{array}{c}\text { E81T1- } \\
\text { Ni1MJH4 }\end{array}$} & 0.0651 & 1.363 & 0.3841 \\
\cline { 2 - 4 } & 0.0105 & 0.0064 & 0.0025 \\
\cline { 2 - 4 } & 0.0348 & 0.931 & 0.0036 \\
\cline { 2 - 4 } & 0.0112 & 0.18 & 0.0096 \\
\hline
\end{tabular}


Table 2. Mechanical properties [1,2]

\begin{tabular}{|c|c|c|c|c|}
\hline Material & $\begin{array}{c}\mathrm{R}_{\mathrm{m}} \\
(\mathrm{Mpa})\end{array}$ & $\begin{array}{c}\mathrm{R}_{\mathrm{p} 0,2} \\
(\mathrm{MPa})\end{array}$ & $\begin{array}{c}\mathrm{A}_{5} \\
(\%)\end{array}$ & $\begin{array}{c}\mathrm{KV}(\mathrm{J}) \\
\mathrm{T}\left({ }^{0} \mathrm{C}\right)\end{array}$ \\
\hline EH 36 & 553 & 442 & 26 & $\begin{array}{c}155.7 \\
-40\end{array}$ \\
\hline $\begin{array}{c}\text { E70C- } \\
\text { 6MH4 }\end{array}$ & 570 & 480 & 28 & $\begin{array}{c}90 \\
-40\end{array}$ \\
\hline $\begin{array}{c}\text { E81T1- } \\
\text { Ni1MJH4 }\end{array}$ & 590 & 510 & 26 & $\begin{array}{c}100 \\
-40\end{array}$ \\
\hline
\end{tabular}

- metal-cored wire E70C-6MH4 according to AWS A5.18 and rutile flux-cored wire E81T1-Ni1MJH4 according to AWS A5.29, with diameters of $1.2 \mathrm{~mm}$. The chemical compositions and the mechanical characteristics of metals deposited with tubular wires, according to certificates quality, are also presented in Table 1 and Table 2;

- mixture of protective gases M21, Corgon $18\left(82 \% \mathrm{Ar}+18 \% \mathrm{CO}_{2}\right)$;

- flat ceramic backing with concave channel;

- four stands for MAG-M mechanized welding in PA, PF, PE and PC positions. The stands were equipped with the universal welding source Phoenix 405 Progress pulse MM TDM and the welding tractor K-BUG 5102.

\subsection{Welding of samples}

The welding of the samples was performed at the Welding Advanced Research Center (SUDAV) of the Department of Manufacturing Engineering from the Faculty of Engineering, "Dunarea de Jos" University of Galaţi.

Within the experimental program, four butt welding samples were welded, in the positions involved in the construction and assembly of naval sections (PA/1G, PC/2G, $\mathrm{PF} / 3 \mathrm{G}$ and $\mathrm{PE} / 4 \mathrm{G})$.

The root layers were made with metalcored wire E70C-6MH4 and RootArc transfer.

The filling and final layers were made with rutile flux-cored wire E81T1-Ni1MJH4 and ForceArc transfer. The layers were deposited with pendulum and stationary on the edges (except for the final layer PC/2G welded sam- ple made of three rows without pendulum). The samples were made on flat ceramic backing with concave channel (Fig. 1).

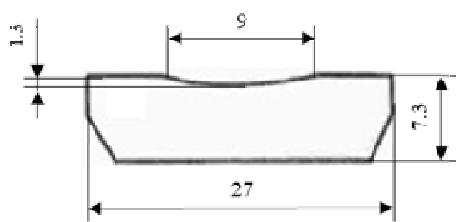

Fig.1. The dimensions of the ceramic backing $[1,2]$

The plates for the samples of EH 36 naval steel, with dimensions of $500 \times 150 \times 10 \mathrm{~mm}$, were processed with air plasma, according to Fig. 2.
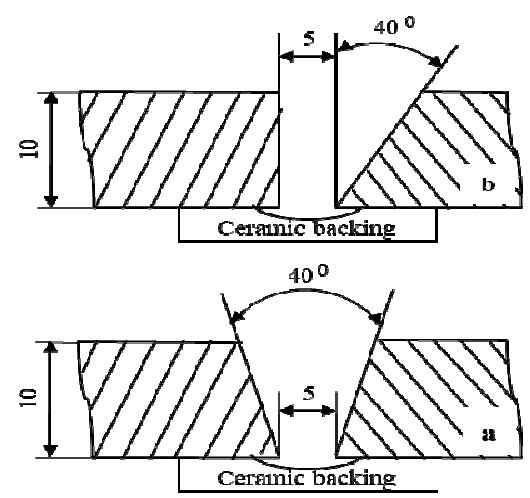

Fig.2. The preparation of plates for welding in positions: a- $\mathrm{PA} / 1 \mathrm{G}, \mathrm{PF} / 3 \mathrm{G}, \mathrm{PE} / 4 \mathrm{G}$;

$$
\text { b- } \mathrm{PC} / 2 \mathrm{G}[1,2]
$$

During the mechanized welding, some of the technological parameters were kept constant: the stationary time at the edges, $\mathrm{t}_{\mathrm{sm}}=0.2$ ms; gas protection flow $\mathrm{Q}_{\mathrm{G}}=18 \mathrm{1} / \mathrm{min}$; gas flow time before welding process start $\mathrm{t}_{\mathrm{bw}}=5 \mathrm{~s}$; gas flow time after welding process end $t_{a w}=5$ $\mathrm{s}$ and distance sample-nozzle $\mathrm{h}_{\mathrm{sn}}=15 \mathrm{~mm}$ [2].

Table 3 centralises the welding process variables wich were applied in the experimental program.

Figure 3 provides illustrations of the welding of the samples, while Figures 4 and Figure 5 present the aspects of the root and bottom layers respectively. 
Table 3. Welding process variables applied in the experimental program.

\begin{tabular}{|c|c|c|c|c|}
\hline \multirow{2}{*}{ Layer } & $\begin{array}{c}\mathrm{v}_{\mathrm{e}} \\
(\mathrm{m} / \mathrm{min})\end{array}$ & $\begin{array}{l}I_{w} \\
\text { (A) }\end{array}$ & $\begin{array}{l}\mathrm{U}_{\mathrm{a}} \\
(\mathrm{V}) \\
\end{array}$ & $\begin{array}{c}\mathrm{v}_{\mathrm{t}} \\
(\mathrm{cm} / \mathrm{min})\end{array}$ \\
\hline & $\begin{array}{c}\mathrm{v}_{\mathrm{p}} \\
(\mathrm{cm} / \mathrm{min})\end{array}$ & $\begin{array}{c}\mathrm{L}_{\mathrm{p}} \\
(\mathrm{mm})\end{array}$ & $\begin{array}{c}\mathrm{V}_{\mathrm{w}} \\
(\mathrm{cm} / \mathrm{min})\end{array}$ & $\begin{array}{c}\mathrm{E}_{\mathrm{l}} \\
(\mathrm{KJ} / \mathrm{mm})\end{array}$ \\
\hline \multicolumn{5}{|c|}{ PA } \\
\hline \multirow{2}{*}{ root } & 4.5 & 183 & 26.5 & 25 \\
\hline & 80 & 6 & 10 & 2.32 \\
\hline \multirow{2}{*}{ final } & 11 & 302 & 31 & 30 \\
\hline & 80 & 8 & 13,7 & 3.28 \\
\hline \multicolumn{5}{|c|}{$\mathrm{PF}$} \\
\hline \multirow{2}{*}{ root } & 2,7 & 103 & 13.8 & 17 \\
\hline & 60 & 6 & 8 & 0.85 \\
\hline \multirow{2}{*}{ fill } & 5.4 & 158 & 18.9 & 27 \\
\hline & 60 & 8 & 14.3 & 0.84 \\
\hline \multirow{2}{*}{ final } & 6 & 167 & 18.9 & 30 \\
\hline & 60 & 10 & 15.5 & 0.98 \\
\hline \multicolumn{5}{|c|}{$\mathrm{PE}$} \\
\hline \multirow{2}{*}{ root } & 2.7 & 103 & 13.8 & 17 \\
\hline & 60 & 6 & 8.13 & 0.84 \\
\hline \multirow{2}{*}{ fill I } & 5.4 & 158 & 18.9 & 27 \\
\hline & 60 & 8 & 14.3 & 0.84 \\
\hline \multirow{2}{*}{ fill II } & 6 & 167 & 18.9 & 30 \\
\hline & 60 & 10 & 15.5 & 0.98 \\
\hline \multirow{2}{*}{ final } & 6 & 167 & 18.9 & 27 \\
\hline & 60 & 12 & 16.7 & 0.91 \\
\hline \multicolumn{5}{|c|}{$\mathrm{PC}$} \\
\hline \multirow{2}{*}{ root } & 5.9 & 170 & 18.9 & 60 \\
\hline & - & - & 60 & 0.26 \\
\hline \multirow{2}{*}{ fill } & 8 & 220 & 25.3 & 60 \\
\hline & - & - & 60 & 0.45 \\
\hline \multirow{6}{*}{ final } & 7 & 192 & 22.5 & 60 \\
\hline & - & - & 60 & 0.35 \\
\hline & 6 & 167 & 18.9 & 60 \\
\hline & - & - & 60 & 0.25 \\
\hline & 5.5 & 160 & 18.9 & 92 \\
\hline & - & - & 92 & 0.16 \\
\hline
\end{tabular}
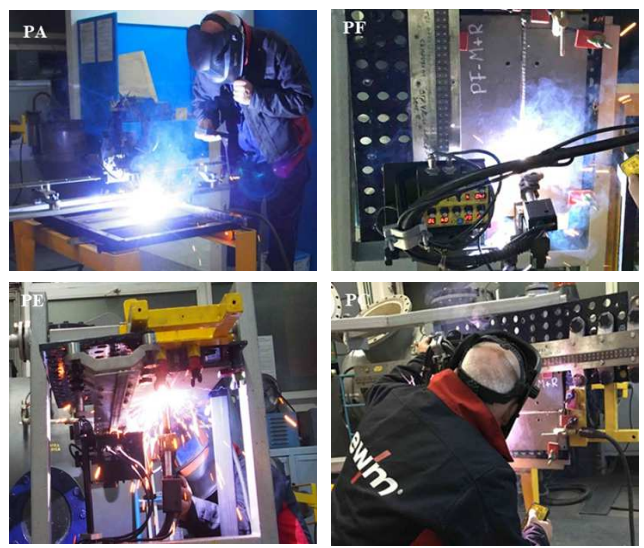

Fig.3. The welding of samples [1,2]
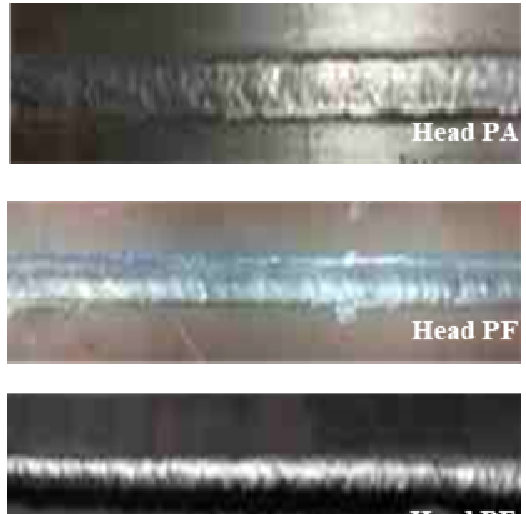

Head PE

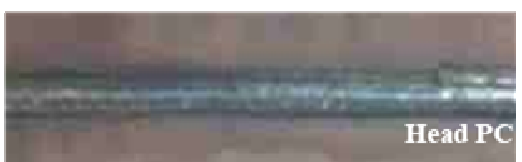

Fig.4. The visual aspects of the head layers [1,2]
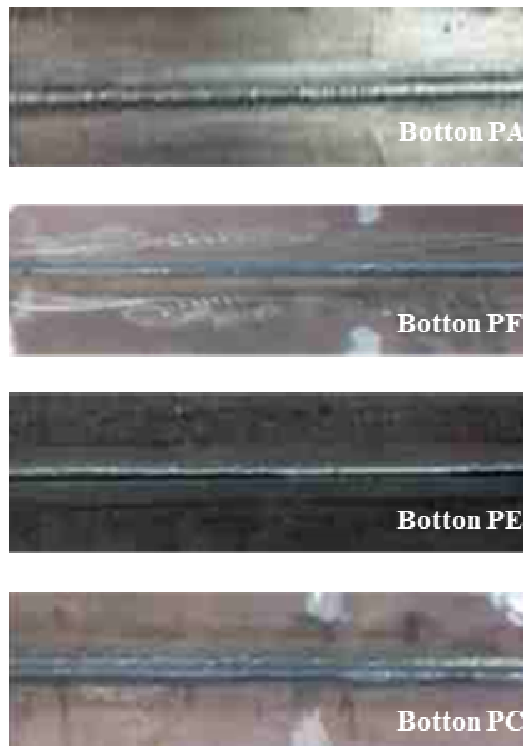

Fig.5. The visual aspects of the botton layers [1,2]

\section{NON-DESTRUCTIVE AND DESTRUCTIVE CONTROL}

According to Lloyd's Register, the butt welded joints have been subjected to [8]: 
- non-destructive control (100\% visual and radiographic);

- destructive control (transverse tensile tests, frontal transverse bending, bending by shock, Vickers HV1 microhardness, macroscopic and microscopic examinations.

\subsection{Non-destructive control}

The visual control was performed after the deposition and cleaning of each layer/line and after the removal of the ceramic support and the brushing of the root (with the open eye and the magnifying glass with $5 \mathrm{x}$ magnification). As a result of the visual control, all four butt welding samples were appropriate (without surface defects). The radiographic control was carried out along the entire length of each sample, within the SC Ductil SA Buzau, using the X-ray installation type MXR-301. After performing the radiographic check, all four butt welding samples were of good quality (admitted).

\subsection{Destructive control}

From each butt welded sample there were removed (Fig. 6) [1,2]:

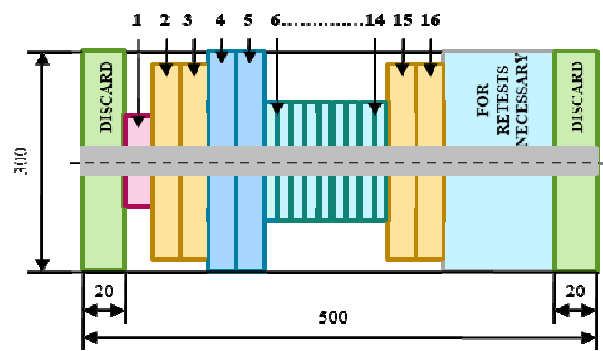

Fig.6. The sampling of specimens $[1,2]$

- a specimen for the macroscopic and microscopic examination and the test of microhardness Vickers HV1, specimen no. 1;

- four specimens for testing at the front transverse bending (two with the compressed root and two with the extended root), at an angle of $180^{\circ}$ on a spindle with a diameter of $40 \mathrm{~mm}$, the specimens no. 2, 3, 15 and 16;

- two flat specimens with the calibrated portion for cross-tensile testing, specimens no. 4 and 5;

- nine specimens for bending test by shock on Charpy V at a temperature of - 20 ${ }^{0} \mathrm{C}$ : three with notch in the centre of welding (SUD) test specimens no. 6, 7 and 8; three with the notch on the fusion line (FL), specimens no. 9, 10 and 11 and three with the notch in the Heat Affected Zone (HAZ) at a distance of $2 \mathrm{~mm}$ from the fusion line (FL), specimens no. 12, 13 and 14 .

\subsubsection{Macroscopic and microscopic ex- aminations}

The macroscopic and microscopic examinations were carried out at a temperature of $25{ }^{\circ} \mathrm{C}$ and a humidity of $50 \%$, within the Laboratory for Metallographic Testing (LAMET) of the "Politehnica" University of Bucharest. After mechanical cutting, the front surfaces of the specimens were rectified and polished with the automatic polishing machine LS $250 \mathrm{~V}$ A.

Macroscopic examination was performed after an attack with $10 \%$ Nital reagent, washing with water and hot air drying, using Olympus GX51 metallographic microscope. The macrostructures of the four samples 1 , which illustrate very clearly the areas of the deposited layers, the crystallization mode (WELD-FL-HAZ) and the lack of internal defects, are shown in Figure 7.
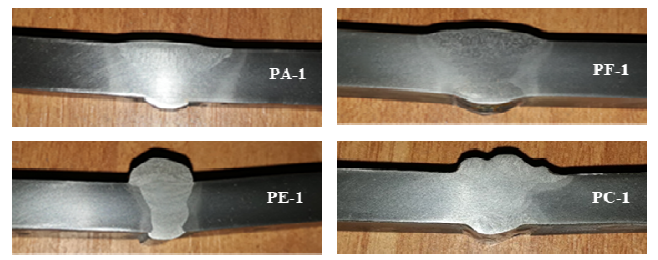

Fig.7. The macrostructures of the samples $[1,2]$

The microscopic examination was performed after an attack with the $2 \%$ Nital reagent, washed with water and dried with hot air, of the same front surfaces of the samples 1, using all the Olympus GX51 metallographic microscope equipped with spe- 
cialized image analysis software - Analysis, SN 8E20014.

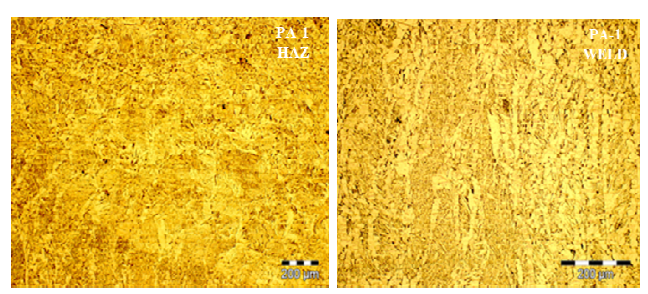

Fig.8. The microstructures of the PA-1 bottom layer test [2]

From the microscopic analyses, the same microstructures were found in the analysed areas, HAZ- increased ferrito-perlitic granulation and coarse ferrite, WELD- acicular ferrite and modified pearlite (Fig. 8).

\subsubsection{Vickers HV1 microhardness tests}

These tests were also performed within the Laboratory for Metallographic Testing (LAMET) of the "Politehnica" University of Bucharest. The determinations were made using the Shimadzu HMV 2TE durometer, at a temperature of $27{ }^{\circ} \mathrm{C}$ and a humidity of 58 $\%$, with an applied force of $1 \mathrm{~N}$ and a measuring time of $10 \mathrm{~s}$. The microhardness was carried out in two directions of investigation (Fig. 9).

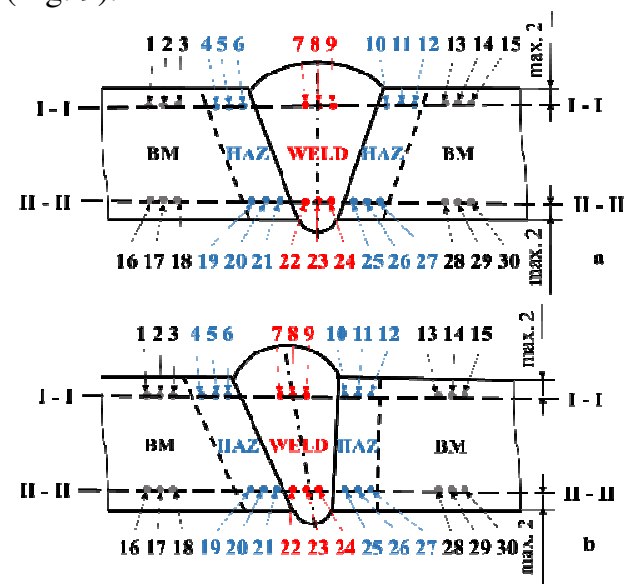

Fig.9. Vickers HV1

microhardness location, on the directions of investigation I - I and II - II: a-PA, PF and PE; b-PC [2]
The Vickers HV1 microhardness was further examined at seven points, in the HAZ overheating sub-zones and in the welded joint axes. Figure 10 shows the averages of the Vickers HV1 microhardness in HAZ and WELD.

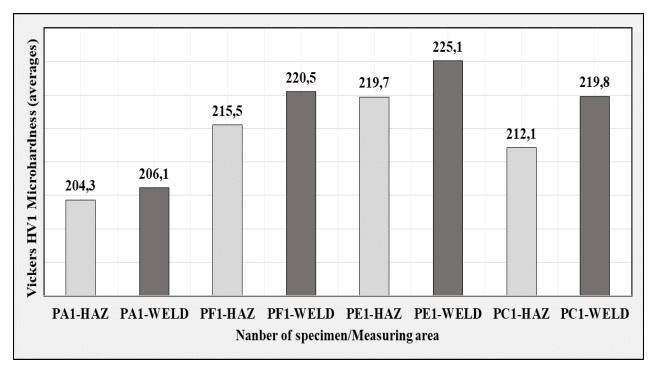

Fig.10. The Vickers HV1 microhardness averages [2]

The values of the Vickers HV1 microhardness tests showed that in the welded joints, no hard and fragile structures were identified, which would endanger the safety in operation.

\subsubsection{Bending testing}

These tests were performed at ambient temperature $23 \pm 5{ }^{0} \mathrm{C}\left(20{ }^{0} \mathrm{C}\right)$, within $\mathrm{SC}$ Ductil SA Buzău company, using the Werkstoff Prufmaschinen bending machine. In Figure 11, the bent specimens are presented after performing the transverse root bend test ( 2 specimens) and the transverse face bend test ( 2 specimens).

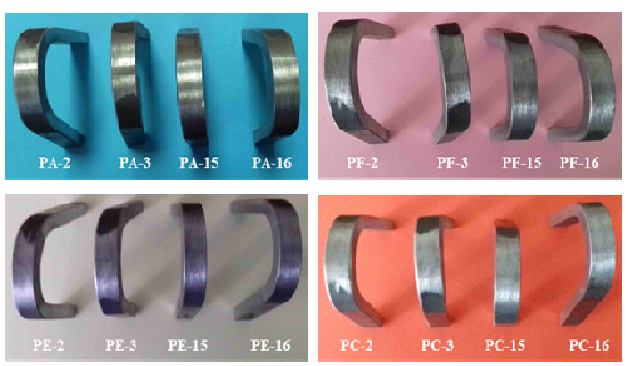

Fig.11. The specimens resulted after performing the (transverse) bending tests [2]

The good results (without defects) of these mechanical tests confirmed the lack of de- 
fects (cracks with lengths over $3 \mathrm{~mm}$ on the extended surface) in welded joints.

\subsubsection{Transverse tensile test}

They were made at ambient temperature $23 \pm 5{ }^{\circ} \mathrm{C}\left(20{ }^{0} \mathrm{C}\right)$, at the SC Ductil SA Buzau company, using the $400 \mathrm{KN}$ Werkstoff Prufmaschinen tensile testing machine. Figure 12 shows the samples resulted after performing the transverse tensile tests.

Figure 13 shows the individual and average tensile strength of the samples subjected to the (mechanical) transverse tensile tests.

It was observed that the failure location of all the specimens subjected to tensile testing was in the base metal (BM). The values at which the failure of the samples took place were close to that of the tensile strength of the base metal (553 MPa).
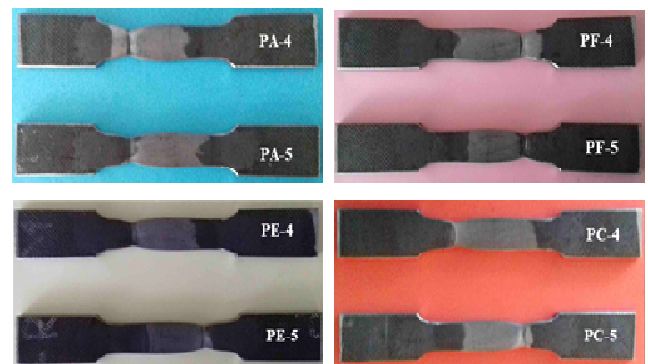

Fig.12. The specimens resulted after performing the (mechanical) transverse tensile tests [2]

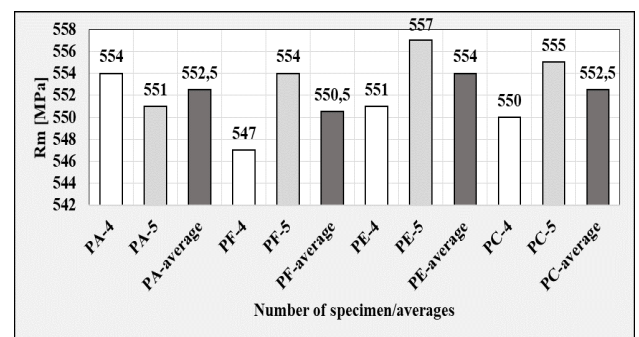

Fig.13. Tensile strength measured during the (mechanical) transverse tensile tests [2]

\subsubsection{Notch impact testing}

$\mathrm{KV}$ notch impact tests were performed at - $20{ }^{0} \mathrm{C}$, (according to Lloyd's Registry), within SC Ductil SA Buzau company, using the Galdabini Impact 300 hammer.
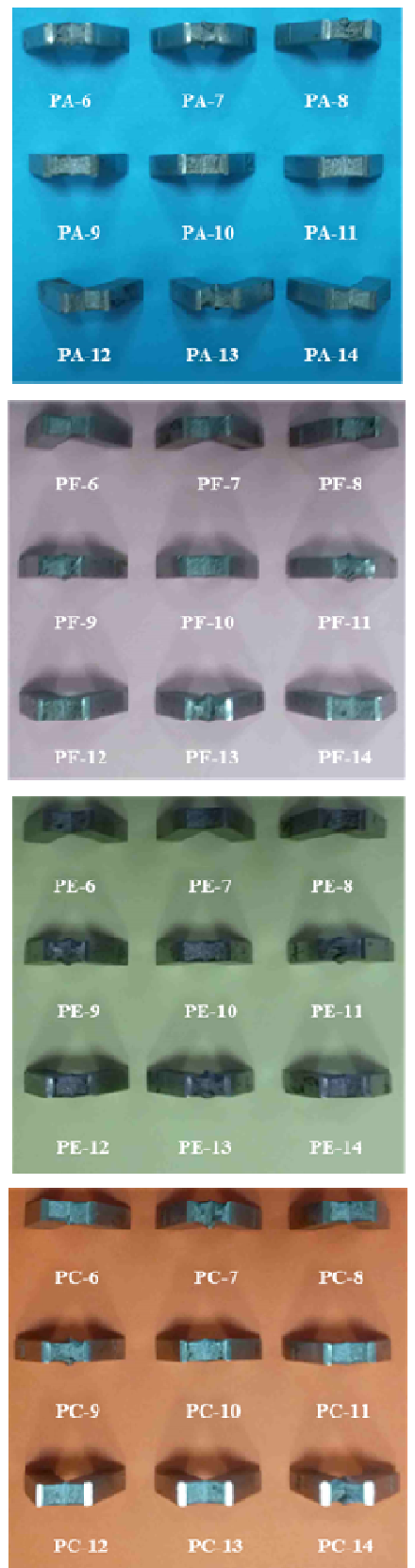

Fig.14. The samples resulted after performing the (mechanical) KV notch impact test [2]

Figure 14 shows the tests after the KV notch impact tests. The individual and average values of the mechanical tests for notch impact tests are centralized in Figure 15. 


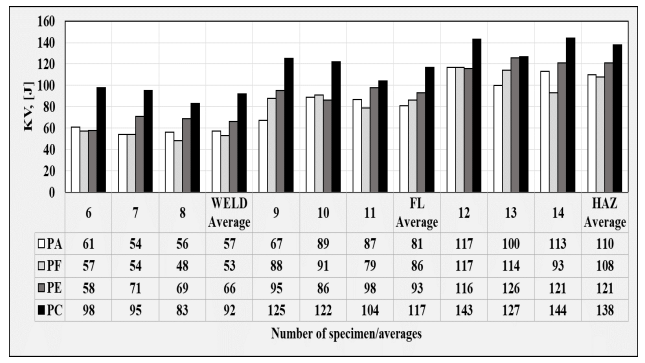

Fig.15. The individual and average values of (mechanical) KV notch impact tests [2]

All the values of the mechanical tests for $\mathrm{KV}$ notch impact tests at the temperature of $20{ }^{\circ} \mathrm{C}$, were above the minimum value of $34 \mathrm{~J}$, according to Lloyd's Register.

\section{CONCLUSIONS}

The good results of the mechanical laboratory tests and the macroscopic and microscopic analyses make it possible to apply the welding technologies of the high strength naval steel EH 36 with a thickness of $10 \mathrm{~mm}$ in the convenient position $\mathrm{PA} / 1 \mathrm{G}$ and in the difficult positions (PC/2G, $\mathrm{PF} / 3 \mathrm{G}$ and $\mathrm{PE} / 4 \mathrm{G})$. According to Lloyd's Register welding technologies can be extended for sheet thicknesses in the range of $3<\mathrm{S} \leq 12$, to $3 . . .2 \mathrm{xS}$, meaning $3 . .20 \mathrm{~mm}$.

\section{Acknowledgements}

The authors express their gratitude to Mr. Razvan Batrinu, General Manager SC Ductil SA Buzău, for support with the welding wire and to Mr. Dr. EWE/IWE Adrian Campurean, General Manager SC Omnisud Welding Research and Innovation SRL Bucharest, for support with welding equipment; without their help this experimental research could not have been achieved.

\section{REFERENCES}

[1]. Florescu, S.N., Mihailescu, D., "Experimental research on mechanized welding $M A G-M$ in narrow gap", Scientific Conference of Doctoral Schools, Perspectives and challenges in doctoral research, 6th Edition of CSSD-UDJG, Galati, 2018.

[2]. Florescu, S.N., 'Experimental research on the behaviour of marine steel EH 36 MAG welding butt mechanized", Report no. 2, "Dunarea de Jos" University of Galati, 2018 (in Romanian).

[3]. Frincu, O., "Theoretical and experimental research mechanized MAG welding on the ceramic backing with ecological cored wire", PhD Thesis, "Dunarea de Jos" University of Galati, 2012 (in Romanian).

[4]. Gheonea, M.C., 'Research on dry hyperbaric underwater mechanized MAG welding with ecological cored wire", $\mathrm{PhD}$ Thesis, "Dunarea de Jos" University of Galati, 2015 (in Romanian).

[5]. Higgins R., Bolton B., 'Materials for engineers and technicians", NEWNES Press, Oxford, USA, 2010.

[6]. Stanciu, L., "Contributions to anti-gravity welding in steel", $\mathrm{PhD}$ Thesis, "Dunarea de Jos" University of Galati, 2010 (in Romanian).

[7]. Suzuki S., Muraoka R., Obinata T., Endo S., Horita T., Omata K., "Steel products for shipbuilding", JFE Technical Report, 2004.

[8]. *** Rules for the Manufacture, Testing and Certification of Materials, Lloyd's Register, July 2018 .

[9]. *** JFE Steel Corporation - Steel plates for shipbuilding, 2013. University of Galati, Fascicle XI Shipbuilding, pp.19-24, 2016.

Paper received on November $5^{\text {th }}, 2019$ 